\title{
Induction of HSP27 and HSP70 by constitutive overexpression of Redd1 confers resistance of lung cancer cells to ionizing radiation
}

\author{
HYEON-OK JIN ${ }^{1}$, SUNG-EUN HONG ${ }^{2}$, JI-YOUNG KIM ${ }^{1}$, MI-RI KIM ${ }^{2}$, YOON HWAN CHANG ${ }^{3}$, \\ YOUNG JUN HONG ${ }^{3}$, JIN KYUNG LEE ${ }^{1,3}$ and IN-CHUL PARK ${ }^{2}$ \\ ${ }^{1}$ KIRAMS Radiation Biobank, ${ }^{2}$ Division of Basic Radiation Bioscience, ${ }^{3}$ Department of Laboratory Medicine, \\ Korea Cancer Center Hospital, Korea Institute of Radiological and Medical Sciences, Seoul 01812, Republic of Korea
}

Received October 12, 2018; Accepted February 26, 2019

DOI: $10.3892 / o r .2019 .7036$

\begin{abstract}
Redd1 is a stress response protein that functions as a repressor of mTORC1, a central regulator of protein translation, resulting in the inhibition of cell growth and metabolism. However, paradoxically, high Redd1 expression favors cancer progression and generates resistance to cancer therapy. Herein, we revealed that constitutive overexpression of Redd1 induced HSP27 and HSP70 expression in lung cancer cells. The expression of Redd1, HSP27 and HSP70 was highly increased in lung cancer tissues compared with that in normal lung tissues. Inhibition of HSP27 or HSP70 suppressed AKT phosphorylation, which was induced by constitutive overexpression of Redd1 and enhanced the inhibitory effects on viability of Redd1-overexpressing cells. Inhibition of AKT phosphorylation resulted in a decrease of HSP27 and HSP70 expression in Redd1-overexpressing cells. These data indicated that HSPs and AKT in Redd1-overexpressing cells positively regulated the function and expression of each other and were involved in lung cancer cell survival. Knockdown of HSP27, HSP70 or AKT enhanced ionizing radiation (IR) sensitivity, particularly in lung cancer cells in which Redd1 was stably overexpressed. Collectively, constitutive overexpression of Redd1 led to HSP27 and HSP70 induction and AKT activation, which were involved in lung cancer cell survival and resistance to IR,
\end{abstract}

Correspondence to: $\mathrm{Dr}$ Hyeon-Ok Jin, KIRAMS Radiation Biobank, Korea Institute of Radiological and Medical Sciences, No. 1511,5F Research Building 2, 75 Nowon-ro, Nowon-gu, Seoul 01812, Republic of Korea

E-mail: hyeonok@kirams.re.kr

Dr In-Chul Park, Division of Basic Radiation Bioscience, Korea Institute of Radiological and Medical Sciences, No. 1511, 5F Research Building 2, 75 Nowon-ro, Nowon-gu, Seoul 01812, Republic of Korea

E-mail: parkic@kirams.re.kr

Key words: AKT, HSP27, HSP70, mTORC1, Redd1 suggesting that Redd1 may be used as a therapeutic target for lung cancer.

\section{Introduction}

Redd1 (also known as RTP801, DDIT4 or Dig2) is a highly conserved stress response gene that is induced by various stresses, such as hypoxia, ionizing radiation (IR), DNA damage and energy depletion (1-4). Redd1 acts primarily as an inhibitor of mTORC1, a central regulator of protein translation, resulting in the inhibition of cell growth and proliferation $(1,5,6)$. However, paradoxically, high Redd1 expression favors cancer progression and generates resistance to cancer therapy. It was reported that Redd1 overexpression could predict poor prognosis of ovarian cancer (7) and promote the development of drug resistance in myeloma cells and prostate cancer cells $(8,9)$. In silico analysis revealed that higher expression levels of Redd1 protein were associated with worse outcomes in acute myeloid leukemia, glioblastoma multiforme, as well as in breast, colon, skin and lung cancer (10). In our previous study, it was demonstrated that constitutive overexpression of Redd1 led to mTORC1 inhibition and to consequent AKT activation which was involved in lung cancer cell survival and resistance to chemotherapeutic drugs (11).

Heat shock proteins (HSPs) are highly conserved molecular chaperones that play essential roles in protein homeostasis, transport processes and signal transduction (12). HSPs protect cells from environmental stress damage by stabilizing the native folding of proteins, and help to sequester severely damaged proteins for degradation. HSPs are classified according to their size, and include HSP90, HSP70, HSP60, HSP40 and HSP27 (13). When proteotoxic damage is present in the cells, the demand on HSPs is increased. In particular, HSP27 and HSP70 are the most strongly induced by anticancer drugs, oxidative stress or IR (14). Overexpressed HSP27 and HSP70 have been revealed to be associated with tumor metastasis, poor prognosis and resistance to chemotherapy (15). Therefore, inhibition of HSP27 and HSP70 has emerged as a novel therapeutic strategy for cancer therapy.

In the present study, we found that constitutive overexpression of Redd1 led to HSP27 and HSP70 induction in lung cancer 
cells. Inhibition of HSP27 or HSP70 suppressed AKT phosphorylation, which was induced by constitutive overexpression of Redd1 and enhanced the inhibitory effects on the viability of Redd1-overexpressing cells. Inhibition of AKT phosphorylation resulted in a decrease of HSP27 and HSP70 expression in Redd1-overexpressing cells. These data indicated that HSPs and AKT in Redd1-overexpressing cells positively and mutually regulated their function and expression, and were involved in lung cancer cell survival. Knockdown of HSP27, HSP70 or AKT enhanced IR sensitivity, particularly in lung cancer cells in which Redd1 was stably overexpressed. Collectively, constitutive overexpression of Redd1 led to AKT activation and HSP27 and HSP70 induction, all of which were involved in lung cancer cell survival and resistance to IR, suggesting that Redd1 may be used as a therapeutic target for lung cancer.

\section{Materials and methods}

Cell culture, reagents and $\gamma$-ionizing radiation. H1299 lung cancer cells that stably overexpressed vector or Redd1 (11) were maintained in RPMI-1640 medium (Welgene, Inc., Gyeongsangbuk-do, Korea) supplemented with $10 \%$ fetal bovine serum (FBS) and $1 \mu \mathrm{g} / \mathrm{ml}$ puromycin (SigmaAldrich; Merck KGaA, Darmstadt, Germany). Cisplatin (cis-diammineplatinum (II) dichloride) and thiazolyl blue tetrazolium bromide (MTT) were purchased from Sigma-Aldrich (Merck KGaA). ${ }^{137}$ Cesium $\left({ }^{137} \mathrm{Cs}\right)$ was used as a source of $\gamma$-radiation (Atomic Energy of Canada Limited, Chalk River, ON, Canada).

Measurement of cell viability. Cell viability was assessed by measuring the mitochondrial conversion of MTT. The proportion of converted MTT was calculated by measuring the absorbance at $570 \mathrm{~nm}$. The results are expressed as the percentage reduction in MTT, assuming that the absorbance of the control cells was $100 \%$. The MTT experiments were repeated 3 times.

Isolation of RNA and reverse transcription PCR analysis. Total RNA was isolated from cells using TRIzol reagent, according to the manufacturer's instructions (Invitrogen; Thermo Fisher Scientific, Inc., Waltham, MA, USA). cDNA primed with oligo dT was prepared from $2 \mu \mathrm{g}$ total RNA using M-MLV Reverse Transcriptase (Invitrogen; Thermo Fisher Scientific, Inc.). The following specific primers were used for PCR: Redd1 (5'-GAA CTCCCACCCCAGATCGG-3' and 5'-CGAGGGTCAGCT GGAAGGTG-3'; 468-bp product) (16), HSP27 5'-AAGGAT GGCGTGGTGGAGATC-3' and 5'-TCGTTGGACTGCGTG GCTAG-3'; 194-bp product) (17), HSP70 5'-ATGAAGCAC TGGCCTTTCCA-3' and 5'-TTGTTCTGGCTGATGTCC TT-3'; 512-bp product) (18), HSP90 (5'-TCTGGAAGATCC CCAGACAC-3' and 5'-AGTCATCCCTCAGCCAGAGA-3'; 189-bp product) (19) and $\beta$-actin (5'-GGATTCCTATGTGGG CGACAG-3' and 5'-CGCTCGGTGAGGATCTTCATG-3'; 438-bp product) (16).

Real-time PCR. Real-time PCR was conducted using TaqMan gene expression assays (Applied Biosystems; Thermo Fisher Scientific, Inc.) on an ABI 7500 Real-Time PCR system (Applied Biosystems; Thermo Fisher Scientific, Inc.). The following primers/probes were used: Reddl (assay ID: Hs01111681_g1), HSP27 (assay ID: Hs00356629_g1) and HSP70 (assay ID: Hs00271229_s1). The expression of each genes were normalised to $\beta$-actin (assay ID: Hs01060665_g1). The thermocycling included an initial step at $50^{\circ} \mathrm{C}$ for $2 \mathrm{~min}$, followed by $10 \mathrm{~min}$ at $95^{\circ} \mathrm{C}$ and 40 cycles of $15 \mathrm{sec}$ at $95^{\circ} \mathrm{C}$ and $1 \mathrm{~min}$ at $60^{\circ} \mathrm{C}$. The fold-change of gene expression was determined using the comparative $\mathrm{Cq}\left(2^{-\Delta \Delta \mathrm{Cq}}\right)$ method (20).

Redd1, HSP27 and HSP70 mRNA levels in lung cancer were analyzed using a commercially available TissueScan Lung Cancer Tissue qPCR panel (Lung Cancer cDNA array II \#HLRT502; Origene Technologies, Inc., Rockville, MD, USA). This contained cDNA from 5 normal lungs, 25 stage I, 6 stage II, 10 stage III, and 2 stage IV lung cancer samples.

siRNAs and transfections. Redd1 (cat. no. sc-45806), AKT1/2 (cat. no. sc-43609), Rictor (cat. no. sc-61478) and control (cat. no. sc-37007) siRNAs were purchased from Santa Cruz Biotechnology, Inc. (Dallas, TX, USA). HSP70 siRNAs (20) were synthesized as follows (Bioneer, Co., Daejeon, Korea): siRNA-HSP70 sense, CGGUUUCUACAUGCAGAGA-dT dT and siRNA-HSP70 antisense, UCUCUGCAUGUAGAA ACCG-dTdT. The transfection experiments were performed using Lipofectamine 2000, according to the manufacturer's instructions (Invitrogen; Thermo Fisher Scientific, Inc.).

Western blot analysis. Cells were lysed in RIPA buffer [50 mM Tris (pH 7.5), $150 \mathrm{mM} \mathrm{NaCl}, 1 \%$ Triton X-100, 0.1\% SDS, $1 \%$ sodium deoxycholate, $5 \mathrm{mM}$ EDTA, $100 \mathrm{mM} \mathrm{NaF}$ and $1 \mathrm{mM} \mathrm{Na} \mathrm{VO}_{4}$ ] containing protease inhibitor cocktail (Roche Diagnostics $\mathrm{GmbH}$, Penzberg, Germany) for $30 \mathrm{~min}$ at $4^{\circ} \mathrm{C}$. Cell lysates were cleared by centrifugation at $12,000 \mathrm{x} \mathrm{g}$ for $20 \mathrm{~min}$ at $4^{\circ} \mathrm{C}$, and the protein concentrations were measured by Bradford reagent (Bio-Rad Laboratories, Inc., Hercules, CA, USA). Protein samples (15-30 $\mu \mathrm{g})$ were separated using $8-12 \%$ SDS-PAGE gels and transferred onto nitrocellulose membranes. The membranes were blocked in Tris-buffered saline (TBS) containing $0.1 \%$ Tween (TBST) and 5\% non-fat dry milk for $1 \mathrm{~h}$ at room temperature. The primary antibodies were incubated overnight at $4^{\circ} \mathrm{C}$. The following antibodies were used: Redd1 (dilution 1:1,000; cat. no. 10638-1-AP) was obtained from ProteinTech Group, Inc. (Rosemont, IL, USA); AKT (dilution 1:1,000; cat. no. 9272), p-AKT at Ser473 (dilution 1:1,000; cat. no. 9271), HSP27 (dilution 1:2,000; cat. no. 2402), Rictor (dilution 1:1,000; cat. no. 2114), S6 (dilution 1:2,000; cat. no. 2217) and p-S6 at Ser240/244 (dilution 1:2,000; cat. no. 4838) were all obtained from Cell Signaling Technology, Inc. (Beverly, MA, USA); HSP70 (dilution 1:2,000; cat. no. ADI-SPA-812) was purchased from Enzo Life Sciences, Inc. (Farmingdale, NY, USA); HSP90 (dilution 1:2,000; cat. no. sc-69703) was obtained from Santa Cruz Biotechnology, Inc.; and $\beta$-actin (dilution 1:3,000; cat. no. A5316) was purchased from Sigma-Aldrich (Merck KGaA). After 3 washes in TBST, the membranes were incubated for $1 \mathrm{~h}$ at room temperature with horseradish peroxidase-conjugated anti-rabbit IgG (dilution 1:3,000; cat. no. sc-2030; Santa Cruz Biotechnology, Inc.) and anti-mouse IgG (dilution 1:3,000; cat. no. sc-2005; Santa Cruz Biotechnology, Inc.) secondary antibodies. The immunoreactive bands were visualized using SuperSignal 
A

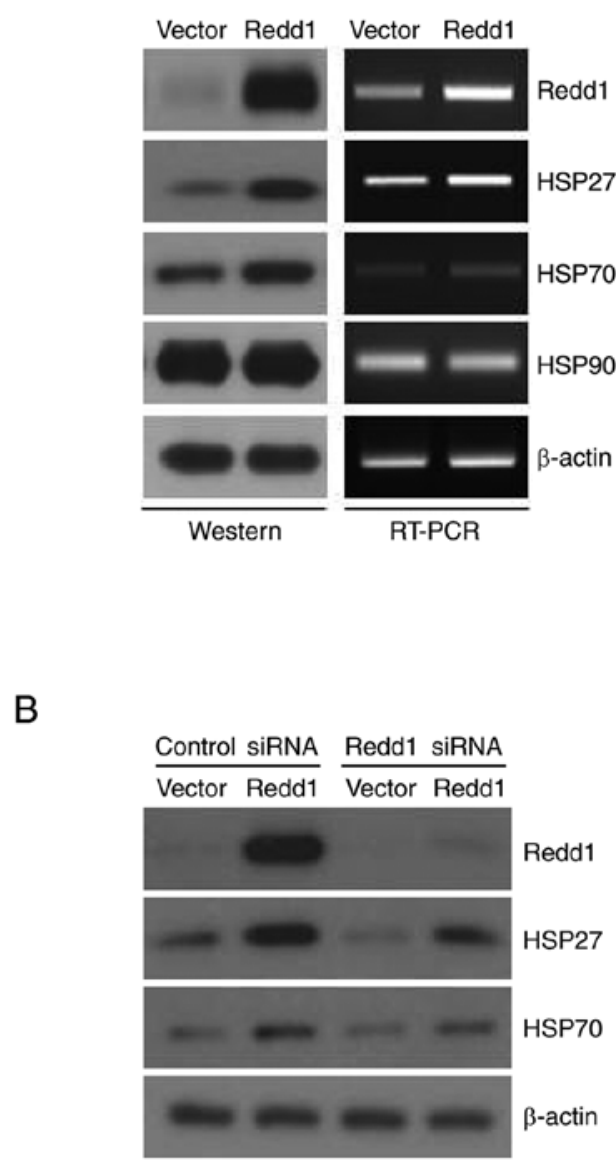

D
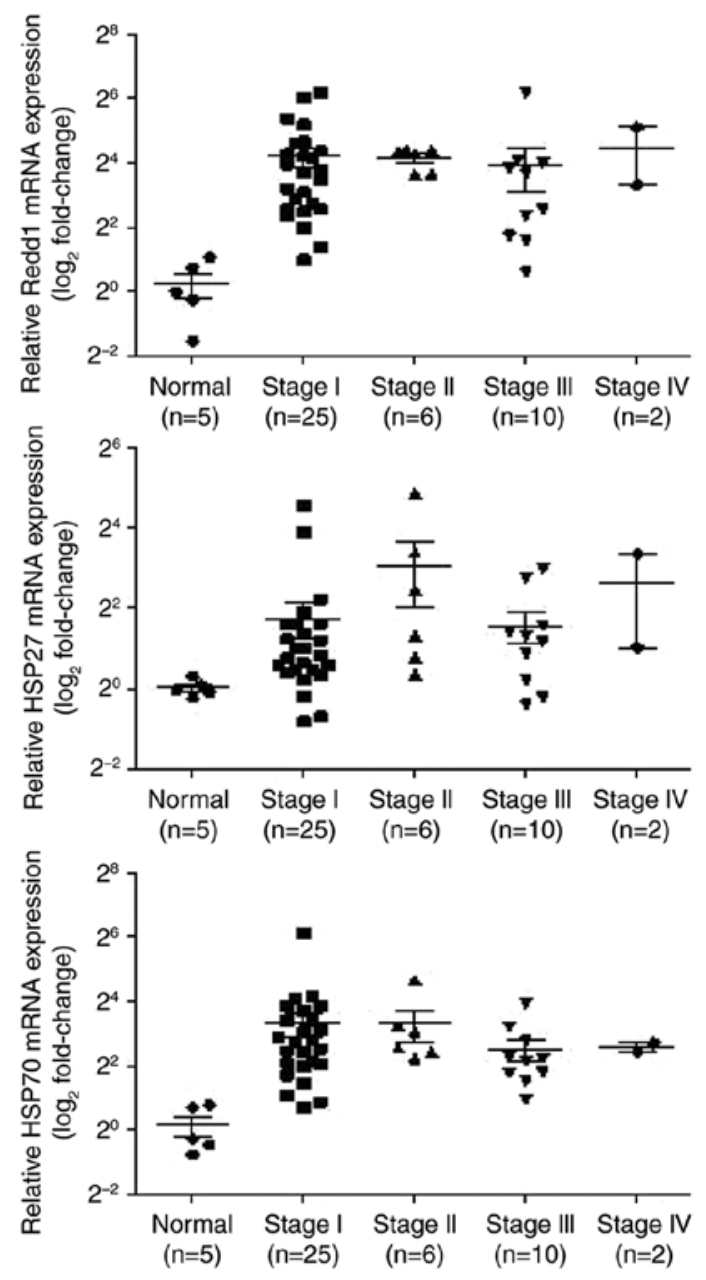
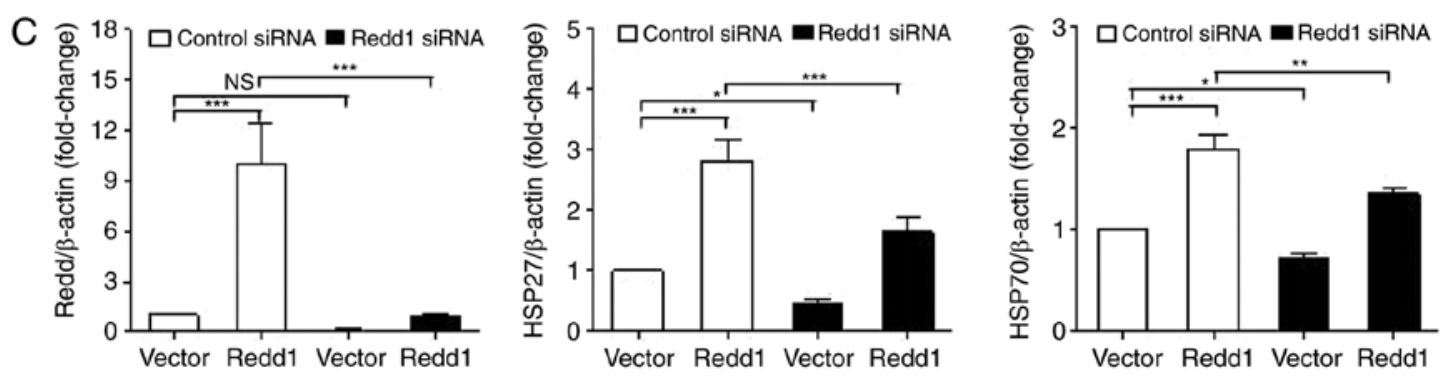

Figure 1. Constitutive overexpression of Redd1 induces HSP27 and HSP70 expression. (A) H1299 cells that stably overexpressed vector or Redd1 were plated at a density of $5 \times 10^{5}$ cells $/ 60 \mathrm{~mm}$ and incubated for $40 \mathrm{~h}$. The indicated protein and mRNA levels were determined by western blotting and RT-PCR, respectively. $\beta$-actin was used as a loading control. (B and C) $\mathrm{H} 1299$ cells that stably overexpressed vector or Redd1 were transiently transfected with Redd1 siRNA for $48 \mathrm{~h}$. The indicated protein levels were determined by (B) western blotting. (C) The protein bands were quantitated by ImageJ software and fold intensity with respect to control after normalization was plotted as histogram $\left({ }^{*} \mathrm{P}<0.05,{ }^{* *} \mathrm{P}<0.01\right.$ and ${ }^{* * * *} \mathrm{P}<0.001$; NS, not significant). (D) Redd1, HSP27 and HSP70 mRNA levels were determined by quantitative real-time PCR in normal lung tissues and lung cancer specimens with different pathologic grades (TissueScan lung cancer cDNA array \#HLRT502; Origene Technologies). Data are normalized to $\beta$-actin expression and presented as the $\log _{2}$-fold-change relative to the normal lung tissue.

West Pico Chemiluminescent substrates (Pierce; Thermo Fisher Scientific Inc.). Where indicated, western blot images were quantified using ImageJ software (version 1.52a; NIH; National Institutes of Health, Bethesda, MD, USA).

Statistical analysis. The results are expressed as the mean \pm standard deviation (SD) of 3 independent experiments. Statistical analysis was performed using one-way analysis of variance (ANOVA), followed by Tukey's post hoc test of GraphPad Prism software (version 5.0; GraphPad Software Inc., San Diego, CA, USA). $\mathrm{P}<0.05, \mathrm{P}<0.01$ and $\mathrm{P}<0.001$ were considered to indicate statistically significant results.

\section{Results}

Expression of HSP27 and HSP70 is increased in Redd1overexpressing cells. We first analyzed proteins with expression levels that had changed in Redd1-overexpressing cells using two-dimensional gel electrophoresis-based proteomic analysis, and we observed increased levels of HSP70 protein (data not shown). Next, we used western blot analysis to further investigate the expression of HSPs in H1299 lung cancer cells that stably overexpressed Redd1. Increased levels of HSP27 and HSP70 protein were observed in Redd1-overexpressing cells (Fig. 1A, left panel). However, constitutive overexpression 
A
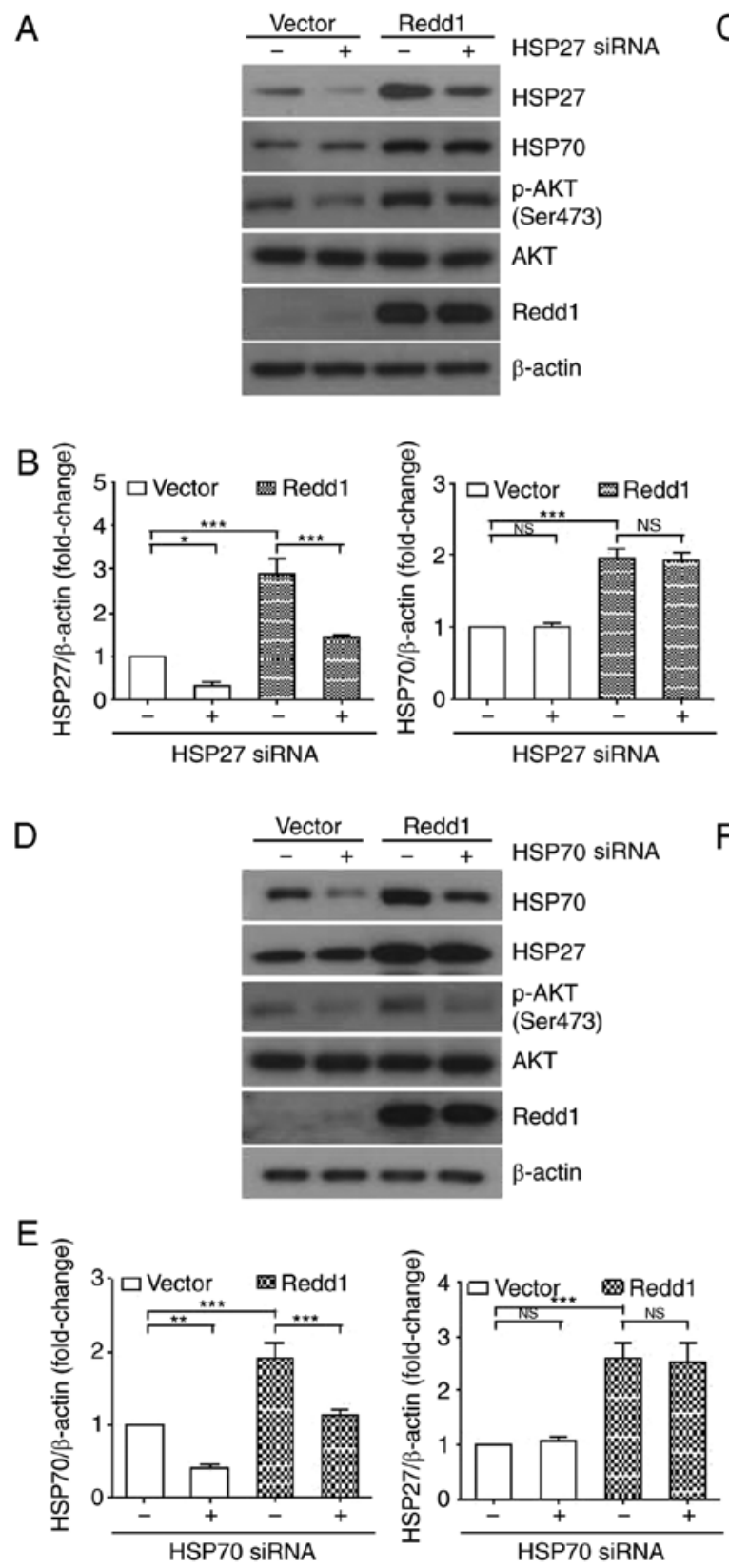

C
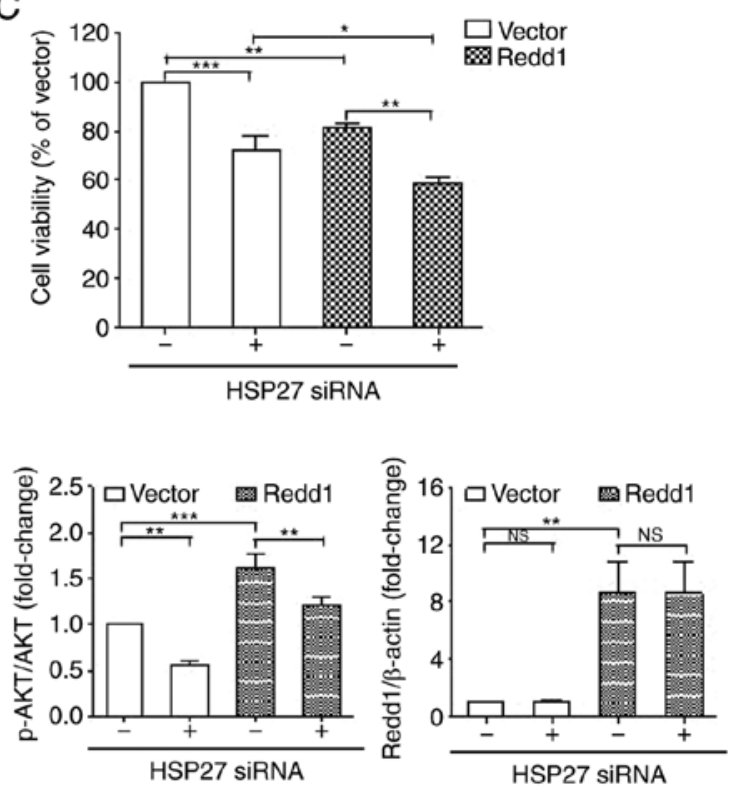

$\mathrm{F}$
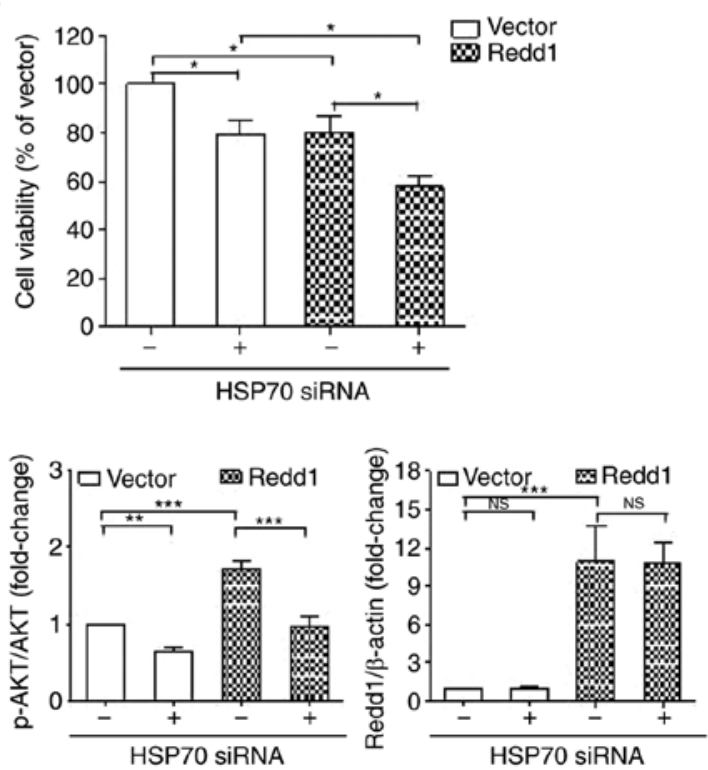

Figure 2. Knockdown of HSP27 or HSP70 inhibits AKT phosphorylation and enhances the inhibitory effects on the viability of Redd1-overexpressing cells. (A-C) H1299 cells that stably overexpressed vector or Redd1 were transiently transfected with HSP27 siRNA for 48 h. (D-F) H1299 cells that stably overexpressed vector or Redd1 were transiently transfected with HSP70 siRNA for $48 \mathrm{~h}$. (A and D) The indicated protein levels were determined by western blot analysis. $\beta$-actin was used as a loading control. (B and E) The protein bands were quantitated by ImageJ software and fold intensity with respect to the control after normalization was plotted as a histogram $\left({ }^{*} \mathrm{P}<0.05,{ }^{* *} \mathrm{P}<0.01\right.$ and ${ }^{* * * *} \mathrm{P}<0.001$; NS, not significant). (C and $\left.\mathrm{F}\right)$ Cell viability was measured using an MTT assay. The data are presented as the mean $\pm \mathrm{SD}\left({ }^{*} \mathrm{P}<0.05,{ }^{* *} \mathrm{P}<0.01\right.$ and ${ }^{* * * *} \mathrm{P}<0.001$; NS, not significant $)$.

of Redd1 did not change the levels of HSP90 protein (Fig. 1A, left panel). Expression of HSP27 and HSP70 mRNA was also increased in Redd1-overexpressing cells (Fig. 1A, right panel). To further ascertain whether constitutive overexpression of Redd1 induced HSP27 and HSP70 expression, Redd1 siRNAs were transfected in Redd1-overexpressing cells. As revealed in Fig. 1B and C, treatment with Redd1 siRNA reduced Redd1-mediated HSP27 and HSP70 expression. Based on these results, it was indicated that constitutive overexpression of Redd1 induces HSP27 and HSP70 expression.

Clinically, increased expression of HSP27 and HSP70 has been shown in high-grade malignant tumors (21-23). Redd1 expression was significantly increased in non-small lung cancer tissues compared with that in normal lung tissues (24). To evaluate HSP27, HSP70 and Redd1 mRNA expression in the different stages of lung cancer, we used a commercially available Lung Cancer Tissue qPCR panel. This included cDNAs obtained from 48 patients with histopathologically confirmed lung cancer, representing all stages (stage $I, n=25$; stage $I I, n=6$; stage III, $n=10$; stage IV, $n=2)$, and normal lung samples $(n=5)$. Redd1, HSP27 and HSP70 mRNA levels were higher in lung cancer tissues than in normal lung tissues (Fig. 1D).

Knockdown of HSP27 or HSP70 inhibits AKT phosphorylation and enhances the inhibitory effects on the viability of Redd1-overexpressing cells. HSP27 has been reported to control 
apoptosis by regulating the AKT signaling pathway $(25,26)$. We previously reported that constitutive overexpression of Redd1 resulted in AKT activation, which was involved in lung cancer cell survival (11). Thus, we examined AKT phosphorylation levels and viability in Redd1-overexpressing cells following treatment with a siRNA against HSP27. As anticipated, treatment with HSP27 siRNA resulted in decreased levels of AKT phosphorylation, which was induced by constitutive overexpression of Redd1 (Fig. 2A and B). Moreover, cell viability was significantly reduced in the HSP27 siRNA-treated, Redd1-overexpressing cells when compared with the control siRNA-treated, Redd1-overexpressing cells (Fig. 2C). However, knockdown of HSP27 did not affect the levels of HSP70 in either the vector or the Redd1-overexpressing cells (Fig. 2A and B).

Next, we examined AKT phosphorylation levels and viability in Redd1-overexpressing cells following treatment with a siRNA against HSP70. HSP70 siRNA inhibited AKT phosphorylation which was induced by constitutive overexpression of Redd1 (Fig. 2D and E), and enhanced the inhibitory effects on the viability of Redd1-overexpressing cells (Fig. 2F). However, knockdown of HSP70 did not affect the levels of HSP27 in either the vector or the Redd1-overexpressing cells (Fig. 2D and E). These data indicated that HSP27 and HSP70 induction by constitutive overexpression of Redd1 was required for AKT phosphorylation, and was involved in lung cancer cell survival.

Inhibition of AKT phosphorylation reduces HSP27 and HSP70 expression induced by constitutive overexpression of Redd1. To examine the effects of AKT on HSP27 and HSP70 expression induced by constitutive overexpression of Redd1, we investigated the expression of HSP27 and HSP70 following treatment with AKT1/2 siRNA or perifosine, a selective AKT inhibitor. As revealed in Fig. 3A and B, depletion of Akt by siRNAs or inhibition of AKT by perifosine suppressed Redd1-induced HSP27 and HSP70 expression, indicating that AKT activity was required for HSP27 and HSP70 expression in Redd1-overexpressing cells. Treatment of AKT1/2 siRNA or perifosine also further enhanced the inhibition of mTORC1 activity by Redd1, as judged by the decrease in S6 phosphorylation. We previously reported that Redd1-induced AKT activation was mediated by mTORC2 (11). Thus, we investigated the effects of mTORC2 on Redd1-induced HSP27 and HSP70 expression. The expression of Rictor, a key component of mTORC2, was suppressed by treatment with Rictor siRNA. As revealed in Fig. 3C, Rictor siRNA not only inhibited AKT phosphorylation as previously reported (11), but also decreased HSP27 and HSP70 expression in Redd1-overexpressing cells. Knockdown of Rictor led to further increases in the cisplatin sensitivity of Redd1-overexpressing cells when compared with that of vector-overexpressing cells (Fig. 3D). These data indicated that mTORC2 activity was required for HSP27 and HSP70 expression in Redd1-overexpressing cells.

Inhibition of HSP27, HSP70 or AKT increases the sensitivity of Reddl-overexpressing cells to IR. Radiation therapy for lung cancer is effective for destroying cancer cells and shrinking tumors. Thus, H1299 cells that stably overexpressed vector or Redd1 were exposed to increasing doses of IR for $24 \mathrm{~h}$. The cell viability rate was $>80 \%$, despite the exposure of both cells to 5 Gy of IR (Fig. 4A). IR increased the levels of HSP27 and HSP70 expression and AKT phosphorylation in a dose-dependent manner in H1299 cells that stably overexpressed vector or Redd1 (Fig. 4B). Transfection of HSP27, HSP70 or AKT1/2 siRNAs in Redd1-overexpressing cells led to further increases in IR sensitivity when compared with the control siRNA-treated, Redd1-overexpressing cells (Fig. 4C). These data indicated that inhibition of HSP27, HSP70, or AKT enhanced IR sensitivity, particularly in cells in which Redd1 was stably overexpressed.

\section{Discussion}

Redd1 (also known as RTP801, DDIT4 or Dig2) acts as a negative regulator of mechanistic target of rapamycin complex I (mTORC1), which integrates diverse signals to regulate cell growth and metabolism $(1,5,6)$. In the present study, we revealed that constitutive overexpression of Redd1 induced HSP27 and HSP70 expression. Clinically, increased expression of HSP27 and HSP70 has been monitored in high-grade malignant tumors, such as osteosarcoma, leukemia, breast, ovarian and endometrial cancer, and renal cell carcinoma (21-23). Redd1 was significantly increased in non-small cell lung cancer (NSCLC) tissue compared with normal lung tissue (24). In the present study, qRT-PCR human lung cancer tissue cDNA arrays demonstrated that Redd1, HSP27 and HSP70 mRNA expression levels were increased in lung cancer tissue compared with those in normal lung tissue.

Several studies have reported that the resistance to apoptosis and antiproliferative signals observed in cancer cells is actually correlated with HSP27 and HSP70 induction (14). Pre-clinical and patient studies demonstrated that overexpression of HSP27 and HSP70 corresponded with an increased proliferation of malignant cells, and that the inhibition of HSP27 and HSP70 expression and function reduced the proliferation and increased the susceptibility of tumor cells to chemotherapy and radiotherapy (27-29). Disruption of HSP27 or HSP70 enhanced the viability of Redd1-overexpressing H1299 lung cancer cells (Fig. 2). Ionizing radiation (IR) increased HSP27 and HSP70 expression levels in a dose-dependent manner in cells that stably overexpressed vector or Redd1 (Fig. 4B). The inhibition of HSP27 and HSP70 with siRNA in Redd1-overexpressing cells led to further increases in IR sensitivity when compared with the vector-overexpressing cells (Fig. 4C). These data indicated that HSP27 and HSP70 induction, which occured as a consequence of the constitutive overexpression of Redd1, played a role in lung cancer cell survival and resistance to IR.

Several studies have shown that HSP27 and HSP70 activate an adaptive mechanism to preserve cell survival through AKT signalling (30,31). The AKT signaling pathway was also revealed to regulate the expression of HSP27 and HSP70, which contributed to tumor cell survival $(32,33)$. We also observed that inhibition of HSP27 or HSP70 function suppressed AKT phosphorylation induced by the constitutive overexpression of Redd1, and the inhibition of AKT function suppressed Redd1-mediated HSP27 or HSP70 expression. These data indicated that heat shock proteins (HSPs) and AKT 
A

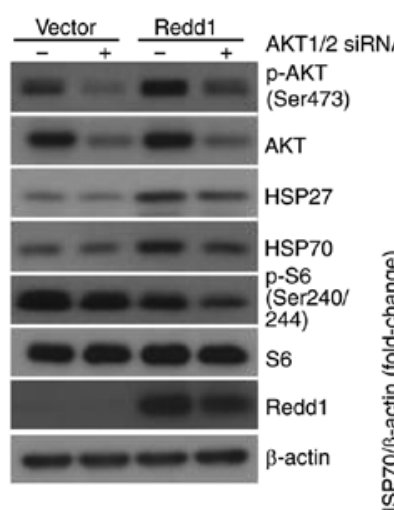

B

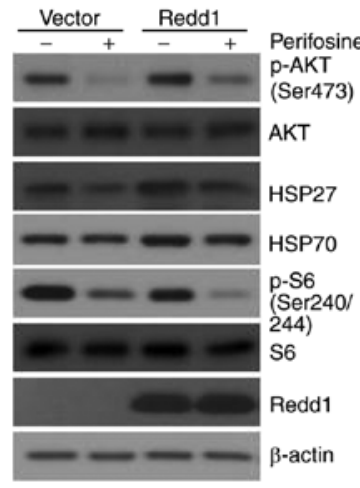

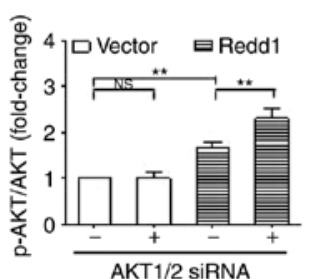
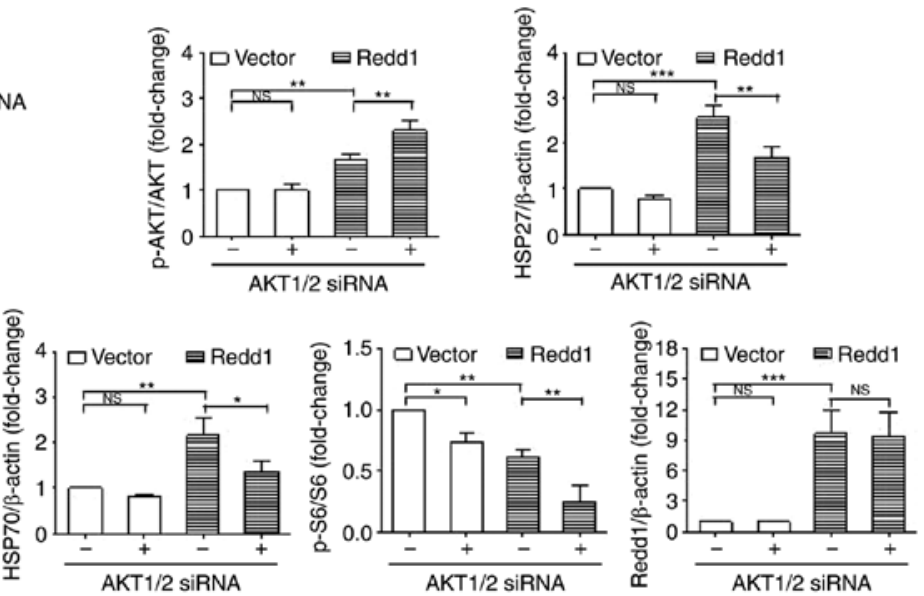
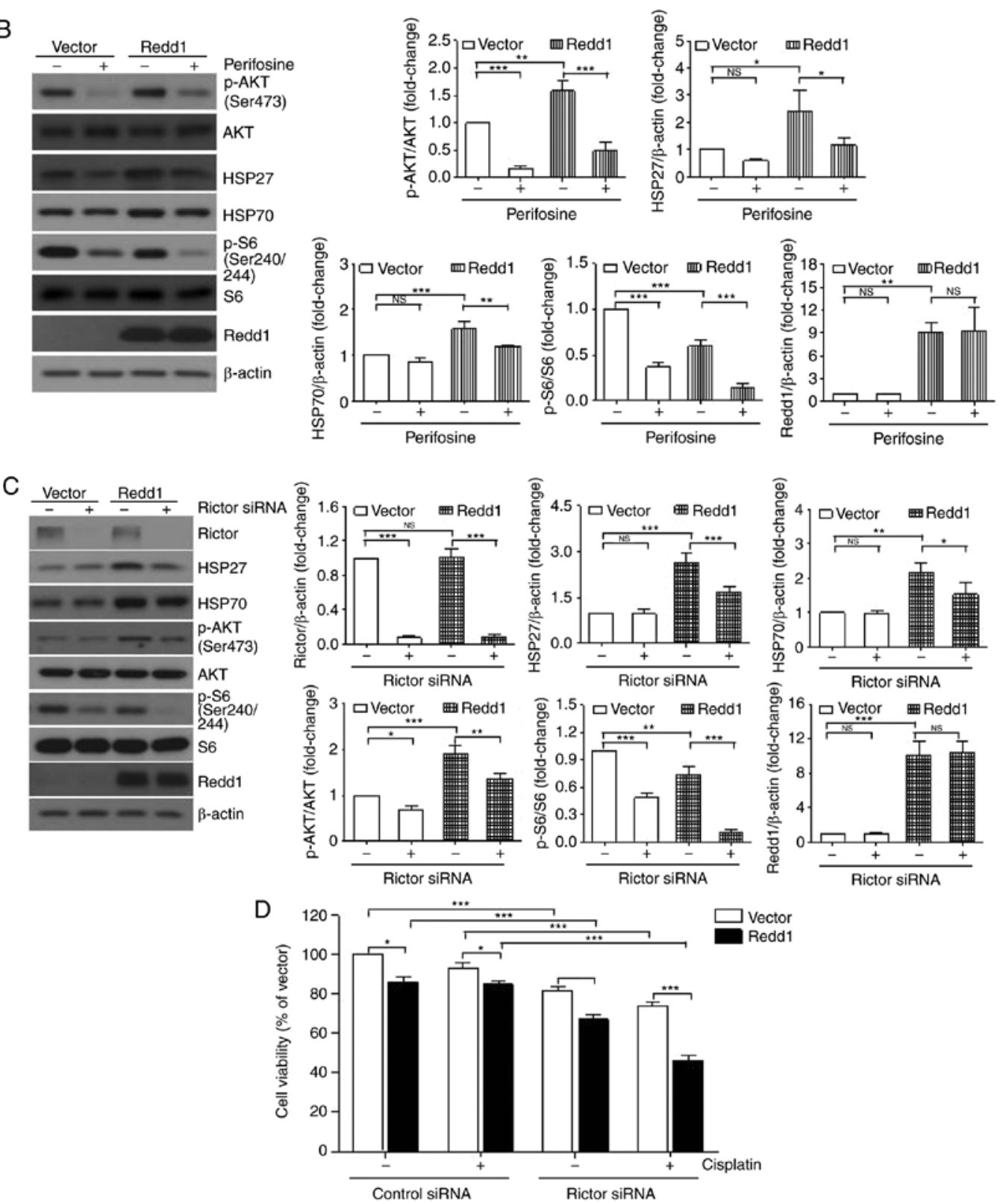

Figure 3. Inhibition of AKT or Rictor reduces HSP27 and HSP70 expression induced by the constitutive overexpression of Redd1. (A) H1299 cells that stably overexpressed vector or Redd1 were transiently transfected with AKT1/2 siRNA for $48 \mathrm{~h}$. (B) H1299 cells that stably overexpressed vector or Redd1 were treated with $5 \mu \mathrm{M}$ perifosine for $48 \mathrm{~h}$. (C) H1299 cells that stably overexpressed vector or Redd1 were transiently transfected with Rictor siRNA for $48 \mathrm{~h}$. (A-C, left panels) The indicated protein levels were determined by western blot analysis. (A-C, right panels) The protein bands were quantitated by ImageJ software and fold intensity with respect to the control after normalization was plotted as a histogram $\left({ }^{*} \mathrm{P}<0.05,{ }^{* *} \mathrm{P}<0.01\right.$ and ${ }^{* * *} \mathrm{P}<0.001$; NS, not significant). (D) H1299 cells that stably overexpressed vector or Redd1 were transiently transfected with Rictor siRNA for $16 \mathrm{~h}$ and subsequently treated with $5 \mu \mathrm{M}$ cisplatin for $24 \mathrm{~h}$. Cell viability was measured using an MTT assay. The data are presented as the mean $\pm \mathrm{SD}\left({ }^{*} \mathrm{P}<0.05\right.$ and ${ }^{* * *} \mathrm{P}<0.001$; NS, not significant). 

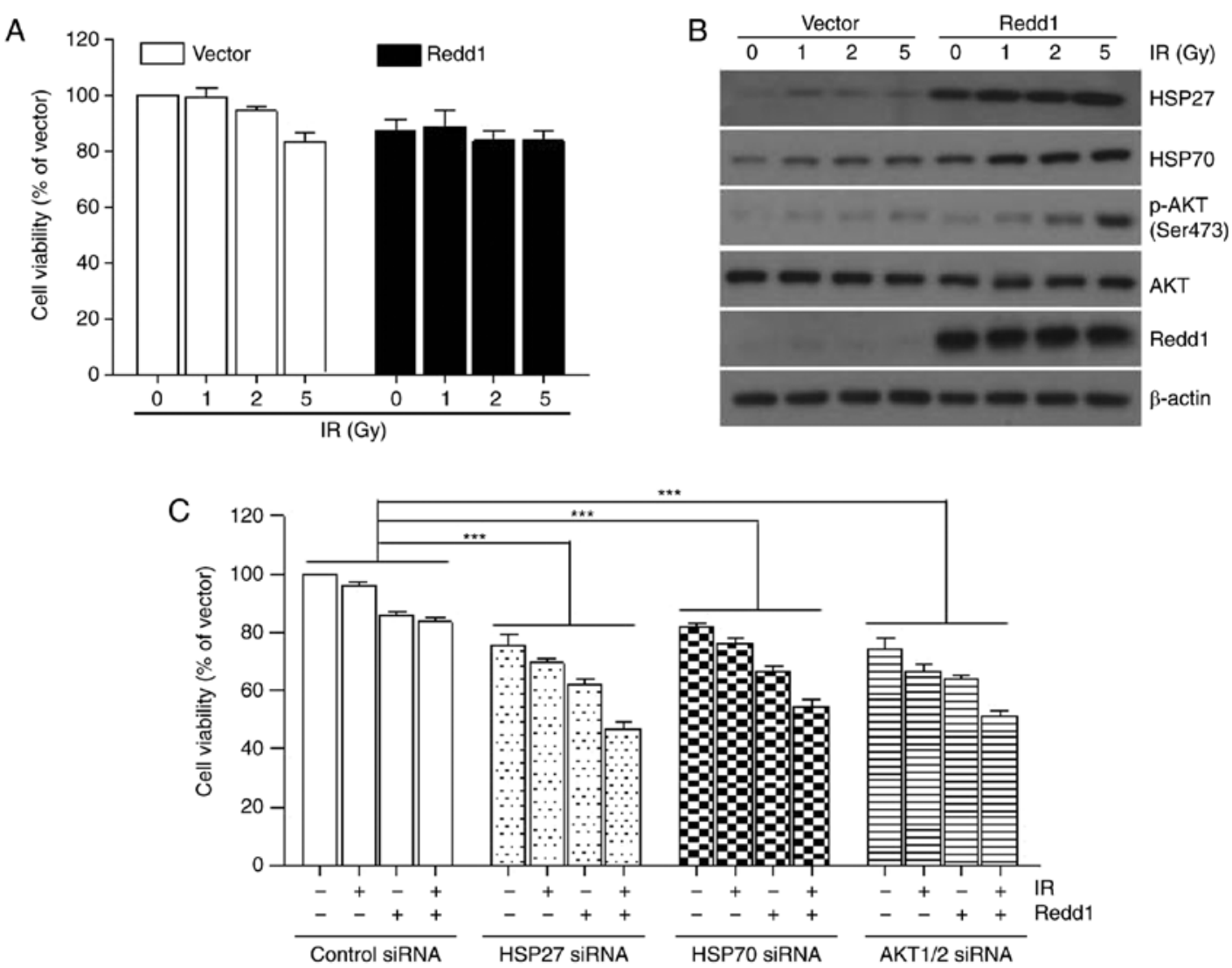

Figure 4. Inhibition of HSP27, HSP70 or AKT1/2 in H1299 cells that stably overexpress Redd1 increases sensitivity to IR. (A and B) H1299 cells that stably overexpressed vector or Redd1 were exposed to the indicated doses of IR for $24 \mathrm{~h}$. (C) H1299 cells that stably overexpressed vector or Redd1 were transiently transfected with control, HSP27, HSP70 or AKT1/2 siRNA for $16 \mathrm{~h}$, and subsequently exposed to $5 \mathrm{~Gy}$ of IR for $24 \mathrm{~h}$. (A and C) Cell viability was measured using an MTT assay. The data are presented as the mean $\pm \mathrm{SD}\left({ }^{* * *} \mathrm{P}<0.001\right)$. (B) The indicated protein levels were determined by western blot analysis. $\beta$-actin was used as a loading control. The blots shown are representative of 2 independent experiments. IR, ionizing radiation.

positively regulated each other in Redd1-overexpressing cells, and that they were involved in lung cancer cell survival.

We previously reported that Redd1-induced AKT activation was mediated by mTORC2 (11). Thus, we investigated the effects of mTORC2 on Redd1-induced HSP27 and HSP70 expression. Inhibition of mTORC2 using Rictor siRNA led to decreases in HSP27 and HSP70 expression and further increases in cisplatin sensitivity in Redd1-overexpressing cells (Fig. 3C and D), suggesting that mTORC2 activity was partially required for HSP27 and HSP70 expression in Redd1-overexpressing cells.

Collectively, constitutive overexpression of Redd1 led to HSP27 and HSP70 induction and AKT activation, all of which were involved in lung cancer cell survival, suggesting that Redd1 may be used as a therapeutic target for lung cancer.

\section{Acknowledgements}

Not applicable.

\section{Funding}

The present study was supported by grants from the Basic Science Research Program through the National Research Foundation of Korea (NRF) funded by the Ministry of
Education (NRF-2017R1D1A1B03029209/50604-2019), the Mid-Career Researchers Program through the NRF funded by the Ministry of Science and ICT (MIST) (NRF-2 017R1A2B2008398/50649-2019) and the Korea Institute of Radiological and Medical Sciences (KIRAMS) funded by the MIST (50531-2019), Republic of Korea.

\section{Availability of data and materials}

The authors declare that the materials included in the manuscript, including all relevant raw data, will be freely available to any researchers who wish to use them for non-commercial purposes, while preserving any necessary confidentiality and anonymity.

\section{Authors' contributions}

HOJ and ICP developed the concept and designed the study. HOJ, SEH, JYK and MRK performed the experiments. YHC, YJH and JKL provided technical support and conceptual advice. HOJ and ICP wrote the manuscript. HOJ, YHC, YJH, JKL and ICP reviewed and edited the manuscript. All authors read and approved the manuscript and agree to be accountable for all aspects of the research in ensuring that the accuracy or integrity of any part of the work are appropriately investigated and resolved. 


\section{Ethics approval and consent to participate}

Not applicable.

\section{Patient consent for publication}

Not applicable.

\section{Competing interests}

The authors declare that they have no competing interests.

\section{References}

1. Brugarolas J,Lei K, Hurley RL, Manning BD, Reiling JH,Hafen E, Witters LA, Ellisen LW and Kaelin WG Jr: Regulation of mTOR function in response to hypoxia by REDD1 and the TSC1/TSC2 tumor suppressor complex. Genes Dev 18: 2893-2904, 2004.

2. Reiling JH and Hafen E: The hypoxia-induced paralogs Scylla and Charybdis inhibit growth by down-regulating S6K activity upstream of TSC in Drosophila. Genes Dev 18: 2879-2892, 2004

3. Ellisen LW, Ramsayer KD, Johannessen CM, Yang A, Beppu H, Minda K, Oliner JD, McKeon F and Haber DA: REDD1, a developmentally regulated transcriptional target of p63 and p53, links p63 to regulation of reactive oxygen species. Mol Cell 10: 995-1005, 2002.

4. Sofer A, Lei K, Johannessen CM and Ellisen LW: Regulation of mTOR and cell growth in response to energy stress by REDD1. Mol Cell Biol 25: 5834-5845, 2005.

5. DeYoung MP, Horak P, Sofer A, Sgroi D and Ellisen LW: Hypoxia regulates TSC1/2-mTOR signaling and tumor suppression through REDD1-mediated 14-3-3 shuttling. Genes Dev 22: 239-251, 2008

6. Corradetti MN, Inoki K and Guan KL: The stress-inducted proteins RTP801 and RTP801L are negative regulators of the mammalian target of rapamycin pathway. J Biol Chem 280: 9769-9772, 2005.

7. Jia W, Chang B, Sun L, Zhu H, Pang L, Tao L, Zou H, Du J, Dong Y, Qi Y, et al: REDD1 and p-AKT over-expression may predict poor prognosis in ovarian cancer. Int J Clin Exp Pathol 7 : 5940-5949, 2014.

8. Decaux O,Clément M, Magrangeas F, Gouraud W, Charbonnel C, Campion L, Loiseau HA and Minvielle S: Inhibition of mTORC1 activity by REDD1 induction in myeloma cells resistant to bortezomib cytotoxicity. Cancer Sci 101: 889-897, 2010.

9. Barakat DJ, Mendonca J, Barberi T, Zhang J, Kachhap SK, Paz-Priel I and Friedman AD: C/EBP $\beta$ regulates sensitivity to bortezomib in prostate cancer cells by inducing $R E D D 1$ and autophagosome-lysosome fusion. Cancer Lett 375: 152-161, 2016.

10. Pinto JA, Rolfo C, Raez LE, Prado A, Araujo JM, Bravo L, Fajardo W, Morante ZD, Aguilar A, Neciosup SP, et al: In silico evaluation of DNA Damage Inducible Transcript 4 gene (DDIT4) as prognostic biomarker in several malignancies. Sci Rep 7: $1526,2017$.

11. Jin HO, Hong SE, Kim JH, Choi HN, Kim K, An S, Choe TB, Hwang CS, Lee JH, Kim JI, et al: Sustained overexpression of Redd1 leads to Akt activation involved in cell survival. Cancer Lett 336: 319-324, 2013.

12. Vahid S, Thaper D, Gibson KF, Bishop JL and Zoubeidi A: Molecular chaperone Hsp27 regulates the Hippo tumor suppressor pathway in cancer. Sci Rep 6: 31842, 2016.

13. Seigneuric R, Mjahed H, Gobbo J, Joly AL, Berthenet K, Shirley $\mathrm{S}$ and Garrido C: Heat shock proteins as danger signals for cancer detection. Front Oncol 1: 37, 2011.

14. Garrido C, Brunet M, Didelot C, Zermati Y, Schmitt E and Kroemer G: Heat shock proteins 27 and 70: Anti-apoptotic proteins with tumorigenic properties. Cell Cycle 5: 2592-2601, 2006.

15. Lianos GD, Alexiou GA, Mangano A, Mangano A, Rausei S, Boni L, Dionigi G and Roukos DH: The role of heat shock proteins in cancer. Cancer Lett 360: 114-118, 2015.
16. Jin HO, Seo SK, Woo SH, Kim ES, Lee HC, Yoo DH, Choe TB, Hong SI, Kim JI and Park IC: SP600125 negatively regulates the mammalian target of rapamycin via ATF4-induced Redd1 expression. FEBS Lett 583: 123-127, 2009.

17. Sheng B, Qi C, Liu B, Lin Y, Fu T and Zeng Q: Increased HSP27 correlates with malignant biological behavior of non-small cell lung cancer and predicts patient's survival. Sci Rep 7: 13807, 2017.

18. Endo H, Yano M, Okumura Y and Kido H: Ibuprofen enhances the anticancer activity of cisplatin in lung cancer cells by inhibiting the heat shock protein 70. Cell Death Dis 5: e1027, 2014.

19. Mehta A, Shervington L, Munje C and Shervington A: A novel therapeutic strategy for the treatment of glioma, combining chemical and molecular targeting of hsp90a. Cancers 3: 4228-4244, 2011.

20. Livak KJ and Schmittgen TD: Analysis of relative gene expression data using real-time quantitative PCR and the $2^{-\Delta \Delta C_{\mathrm{T}}}$ method. Methods 25: 402-408, 2001.

21. Parcellier A, Schmitt E, Brunet M, Hammann A, Solary E and Garrido C: Small heat shock proteins HSP27 and alphaBcrystallin: Cytoprotective and oncogenic functions. Antioxid Redox Signal 7: 404-413, 2005.

22. Santarosa M, Favaro D, Quaia M and Galligioni E: Expression of heat shock protein 72 in renal cell carcinoma: Possible role and prognostic implications in cancer patients. Eur J Cancer 33: 873-877, 1997.

23. Nanbu K, Konishi I, Mandai M, Kuroda H, Hamid AA, Komatsu T and Mori T: Prognostic significance of heat shock proteins HSP70 and HSP90 in endometrial carcinomas. Cancer Detect Prev 22: 549-555, 1998.

24. Su J, Huang H, Ju S and Shi J: Elevated RTP801 promotes cell proliferation in non-small cell lung cancer. IUBMB Life 70: 310-319, 2018.

25. Rane MJ, Pan Y, Singh S, Powell DW, Wu R, Cummins T, Chen Q, McLeish KR and Klein JB: Heat shock protein 27 controls apoptosis by regulating Akt activation. J Biol Chem 278: 27828-27835, 2003.

26. Zhang Y and Shen X: Heat shock protein 27 protects L929 cells from cisplatin-induced apoptosis by enhancing Akt activation and abating suppression of thioredoxin reductase activity. Clin Cancer Res 13: 2855-2864, 2007.

27. Aloy MT, Hadchity E, Bionda C, Diaz-Latoud C, Claude L, Rousson R, Arrigo AP and Rodriguez-Lafrasse C: Protective role of Hsp27 protein against gamma radiation-induced apoptosis and radiosensitization effects of Hsp27 gene silencing in different human tumor cells. Int J Radiat Oncol Biol Phys 70: 543-553, 2008 .

28. Heinrich JC, Tuukkanen A, Schroeder M, Fahrig T and Fahrig R: RP101 (brivudine) binds to heat shock protein HSP27 (HSPB1) and enhances survival in animals and pancreatic cancer patients. J Cancer Res Clin Oncol 137: 1349-1361, 2011.

29. Schultz CR, Golembieski WA, King DA, Brown SL, Brodie C and Rempel SA: Inhibition of HSP27 alone or in combination with pAKT inhibition as therapeutic approaches to target SPARC-induced glioma cell survival. Mol Cancer 11: 20, 2012.

30. Wu R, Kausar H, Johnson P, Montoya-Durango DE, Merchant M and Rane MJ: Hsp27 regulates Akt activation and polymorphonuclear leukocyte apoptosis by scaffolding MK2 to Akt signal complex. J Biol Chem 282: 21598-21608, 2007.

31. Powers MV, Clarke PA and Workman P: Dual targeting of HSC70 and HSP72 inhibits HSP90 function and induces tumor-specific apoptosis. Cancer Cell 14: 250-262, 2008.

32. Chatterjee M, Andrulis M, Stühmer T, Müller E, Hofmann C, Steinbrunn T, Heimberger T, Schraud H, Kressmann S, Einsele $\mathrm{H}$ and Bargou RC: The PI3K/Akt signaling pathway regulates the expression of Hsp70, which critically contributes to Hsp90-chaperone function and tumor cell survival in multiple myeloma. Haematologica 98: 1132-1141, 2013.

33. Ghosh A, Lai C, McDonald S, Suraweera N, Sengupta N, Propper D, Dorudi S and Silver A: HSP27 expression in primary colorectal cancers is dependent on mutation of $K R A S$ and PI3K/AKT activation status and is independent of TP53. Exp Mol Pathol 94: 103-108, 2013. 